\title{
DETERMINISTIC VERSUS STOCHASTIC SEASONAL FRACTIONAL INTEGRATION AND STRUCTURAL BREAKS
}

\author{
Guglielmo Maria Caporale ${ }^{\mathrm{a}}$ \\ Juncal Cunado ${ }^{b}$ \\ Luis A. Gil-Alanac

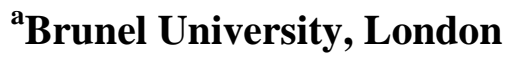 \\ ${ }^{b, c}$ University of Navarra
}

February 2007

\begin{abstract}
This paper considers a general model which allows for both deterministic and stochastic forms of seasonality, including fractional (stationary and nonstationary) orders of integration, and also incorporating endogenously determined structural breaks. Monte Carlo analysis shows that the suggested procedure performs well even in small samples, accurately capturing the seasonal properties of the series, and correctly detecting the break date. As an illustration, the model is estimated for four different US series (output, consumption, imports and exports). The results suggest that the seasonal patterns of these variables have changed over time: specifically, in the second subsample the systematic component of seasonality becomes insignificant, whilst the degree of persistence increases.
\end{abstract}

JEL Classification: C22

Keywords: Deterministic and Stochastic Seasonality, Fractional Integration, Structural Breaks

Corresponding author: Professor Guglielmo Maria Caporale, Brunel University, Uxbridge, Middlesex UB8 3PH, UK. Tel.: +44 (0)1895 266713. Fax: +44 (0)1895 269770. Email: Guglielmo-Maria.Caporale@brunel.ac.uk

The second- and third-named author gratefully acknowledge financial support from the Ministerio de Ciencia y Tecnologia (SEJ2005-07657), Spain. 


\section{Introduction}

This paper analyses seasonality in the presence of structural breaks. Modelling seasonality is still a hotly debated topic in the time series literature. Hylleberg (1986) classifies seasonal models in three categories. The first includes purely deterministic seasonal models, which are characterised by seasonal dummy variables of the form:

$$
y_{t}=\alpha+\sum_{i=1}^{s-1} \gamma_{i} D_{i t}+u_{t}, \quad t=1,2, \ldots
$$

where $\mathrm{y}_{\mathrm{t}}$ is the observed time series data with $\mathrm{s}$ observations per year, $\mathrm{D}_{\mathrm{it}}$ is a seasonal dummy adopting a value 1 if $t$ belongs to the $i^{\text {th }}$ period of the year and 0 otherwise, and $\mathrm{u}_{\mathrm{t}}$ is a white noise. The definition of the seasonal dummy simply allows for the mean of the series to vary by season, and therefore it raises no statistically interesting issues. The reason for using models like (1) is that the factor that might produce the seasonal variation can be readily identified.

A second type of seasonality is the one defined in terms of a seasonal stochastic stationary process, where $\mathrm{y}_{\mathrm{t}}$ is specified as

$$
\phi\left(L^{S}\right) y_{t}=\theta\left(L^{S}\right) u_{t}, \quad t=1,2, \ldots
$$

and $\phi\left(\mathrm{L}^{\mathrm{s}}\right)$ and $\theta\left(\mathrm{L}^{\mathrm{s}}\right)$ are seasonal $\mathrm{AR}$ and MA polynomials with all roots lying outside the unit circle. Finally, if the seasonal component is changing across time, seasonal differencing is usually adopted. In such a case, the process is said to contain seasonal unit roots, and the model is expressed as

$$
\left(1-L^{S}\right) y_{t}=u_{t}, \quad t=1,2, \ldots
$$

Many test statistics have been developed in recent years for testing seasonal unit roots: Dickey, Hasza and Fuller (1984), Hylleberg, Engle, Granger and Yoo (1990), Tam and Reimsel (1997), etc. Nevertheless, all these types of seasonality can coexist in a single framework, which, in its more general form, can be written as: 
$y_{t}=\alpha+\sum_{i=1}^{s-1} \gamma_{i} D_{i t}+x_{t} ; \quad\left(1-L^{S}\right)^{d} x_{t}=u_{t} ; \quad \phi\left(L^{S}\right) u_{t}=\theta\left(L^{S}\right) \varepsilon_{t}$

where the difference between stationary and nonstationary seasonality comes from $d$ being equal to 0 and 1 respectively.

However, the value $d$ in (4) is not necessarily an integer number. If $d$ is allowed to be any real number, the process is said to be seasonally fractionally integrated, with much greater flexibility in the dynamic behaviour of the series (see Gil-Alana, 2005). The notion of a fractional Gaussian noise with seasonality was suggested by Jonas (1981) and extended in a Bayesian framework by Carlin et al. (1985) and Carlin and Dempster (1989). Porter-Hudak (1990) applied a seasonally fractionally integrated model to quarterly US monetary aggregates, and concluded that a fractional ARMA model was more appropriate than the usual ARIMA specification for these series. Other recent empirical papers on seasonal fractional integration are those of Gil-Alana and Robinson (2001) and Gil-Alana (2002).

The present study focuses on the model given by equation (4), extended to incorporate endogenously determined structural breaks. Note that fractional integration (at the zero frequency) has been recently related to structural breaks (see, e.g. Granger and Hyung, 1999; Gourieroux and Jasiak, 2001; Diebold and Inoue, 2001; etc.), and thus we should expect a similar relationship in the presence of seasonality. The outline of the paper is as follows: Section 2 describes the procedure for estimating the parameters in the model. In Section 3 we carry out several Monte Carlo experiments to examine the finite sample behaviour of the seasonal procedure we implement. An empirical application is carried out in Section 4, while Section 5 contains some concluding comments. 


\section{The statistical method}

In this section we present a procedure that enables us to examine the deterministic and stochastic (stationarity/nonstationarity) seasonal nature of the series of interest in a very general framework. This has a number of advantages. Firstly, instead of restricting ourselves to the standard I(0) (stationarity) or I(1) (nonstationarity) cases, we consider the possibility of fractional orders of integration. Secondly, since seasonal dummies are also included in the model along with seasonal fractional/integer differentiation, we are able to consider the models described in Section 1 as special cases within our framework. Thirdly, we allow for structural breaks, with the breakpoint(s) being endogenously determined by the model. For simplicity we start by considering the case of a single break and assume that $\mathrm{y}_{\mathrm{t}}$ is generated as follows:

$$
\begin{aligned}
& y_{t}=\alpha^{(1)}+\sum_{i=1}^{s-1} \gamma_{i}^{(1)} D_{i t}+x_{t} ; \quad\left(1-L^{S}\right)^{d^{(1)}} x_{t}=u_{t}, \quad t=1, \ldots, T_{b}-1, \\
& y_{t}=\alpha^{(2)}+\sum_{i=1}^{s-1} \gamma_{i}^{(2)} D_{i t}+x_{t} ; \quad\left(1-L^{S}\right)^{d^{(2)}} x_{t}=u_{t}, \quad t=T_{b}, \ldots, T,
\end{aligned}
$$

where the $\alpha$ 's and the $\gamma^{\prime}$ s are intercept and dummy coefficients respectively; $d^{(1)}$ and $d^{(2)}$ can be any real number and correspond to the orders of integration of each subsample, $\mathrm{u}_{\mathrm{t}}$ is $\mathrm{I}(0)$, and $\mathrm{T}_{\mathrm{b}}$ is the date of the break which is assumed to be unknown. Note that the model in equations (5) and (6) can also be written as:

$$
\begin{aligned}
& \left(1-L^{s}\right)^{d^{(1)}} y_{t}=\alpha^{(1)} \widetilde{1}_{t}\left(d^{(1)}\right)+\sum_{i=1}^{s-1} \gamma_{i}^{(1)} \widetilde{D}_{i t}\left(d^{(1)}\right)+u_{t}, \quad t=1, \ldots, T_{b}-1, \\
& \left(1-L^{s}\right)^{d^{(2)}} y_{t}=\alpha^{(2)} \widetilde{1}_{t}\left(d^{(2)}\right)+\sum_{i=1}^{s-1} \gamma_{i}^{(2)} \widetilde{D}_{i t}\left(d^{(2)}\right)+u_{t}, \quad t=T_{b}, \ldots, T,
\end{aligned}
$$

where $\widetilde{1}_{t}\left(d^{(i)}\right)=\left(1-L^{S}\right)^{d^{(i)}} 1$, and $\widetilde{D}_{i t}\left(d^{(i)}\right)=\left(1-L^{S}\right)^{d^{(i)}} D_{i t}, \mathrm{i}=1,2$. 
The approach adopted here is based on the least square principle. First, we choose a grid for the values of the fractionally seasonal differencing parameters $d^{(1)}$ and $d^{(2)}$, for example, $d_{j}^{(i)}=0,0.01,0.02, \ldots, 2, \mathrm{i}=1,2$. Then, for a given partition $\left\{\mathrm{T}_{\mathrm{b}}\right\}$ and given $d_{o}^{(1)}, d_{o}^{(2)}$-initial values, we estimate the $\alpha$ 's and the $\gamma^{\prime}$ s by minimising the sum of squared residuals,

$$
\begin{aligned}
& \min \sum_{t=1}^{T_{b}}\left[\left(1-L^{s}\right)^{d_{o}^{(1)}} y_{t}-\alpha^{(1)} \widetilde{1}_{t}\left(d_{o}^{(1)}\right)-\sum_{i=1}^{s-1} \gamma_{i}^{(1)} \widetilde{D}_{i t}\left(d_{o}^{(1)}\right)\right]^{2}+ \\
& \text { w.r.t }\left(\alpha^{(1)} \alpha^{(2)} \gamma_{i}^{(1)} \gamma_{i}^{(2)}\right) \\
& \sum_{t=T_{b}+1}^{T}\left[\left(1-L^{s}\right)^{d_{o}^{(2)}} y_{t}-\alpha^{(2)} \widetilde{1}_{t}\left(d_{o}^{(2)}\right)-\sum_{i=1}^{s-1} \gamma_{i}^{(2)} \widetilde{D}_{i t}\left(d_{o}^{(2)}\right)\right]^{2}
\end{aligned}
$$

for uncorrelated $\mathrm{u}_{\mathrm{t}}$, or, alternatively, using GLS for weakly autocorrelated disturbances. Let $\hat{\alpha}\left(T_{b} ; d_{o}^{(1)}, d_{o}^{(2)}\right)$ and $\hat{\gamma}\left(T_{b} ; d_{o}^{(1)}, d_{o}^{(2)}\right)$ denote the resulting estimates for partition $\left\{\mathrm{T}_{\mathrm{b}}\right\}$ and initial values $d_{o}^{(1)}$ and $d_{o}^{(2)}$. Substituting these estimated values in the objective function, we obtain $\operatorname{RSS}\left(\mathrm{T}_{\mathrm{b}} ; d_{o}^{(1)}, d_{o}^{(2)}\right)$, and minimising this expression for all values of $d_{1 o}$ and $d_{2 o}$ in the grid we obtain:

$$
R S S\left(T_{b}\right)=\arg \min _{\{i, j\}} \operatorname{RSS}\left(T_{b} ; d_{i}^{(1)}, d_{j}^{(2)}\right)
$$

Then, the estimated break date, $\hat{\mathrm{T}}_{\mathrm{k}}$, is such that

$$
\hat{T}_{k}=\arg \min { }_{i=1, \ldots, m} R S S\left(T_{i}\right),
$$

where the minimisation is over all partitions $T_{1}, T_{2}, \ldots, T_{m}$, such that $T_{i}-T_{i-1} \geq|\varepsilon T|$. The regression parameter estimates are the associated least-squares estimates of the estimated k-partition, i.e., $\quad \hat{\alpha}^{(i)}=\alpha^{(i)}\left(\left\{\hat{T}_{k}\right\}\right), \quad \hat{\gamma}_{k}^{(i)}=\gamma_{k}^{(i)}\left(\left\{\hat{T}_{k}\right\}\right), \quad$ and their corresponding differencing parameters, $\hat{d}^{(i)}=d^{(i)}\left(\left\{\hat{T}_{k}\right\}\right)$, for $\mathrm{i}=1$ and 2 . 
The model can be extended to the case of multiple breaks by considering the following specification:

$$
y_{t}=\alpha^{(j)}+\sum_{i=1}^{s-1} \gamma_{i}^{(j)} D_{i t}+x_{t} ; \quad\left(1-L^{s}\right)^{d^{(j)}} x_{t}=u_{t}, \quad t=T_{j-1}+1, \ldots, T_{j},
$$

for $\mathrm{j}=1, \ldots, \mathrm{m}+1, \mathrm{~T}_{0}=0$ and $\mathrm{T}_{\mathrm{m}+1}=\mathrm{T}$. Then, the parameter $\mathrm{m}$ is the number of changes. The break dates $\left(\mathrm{T}_{1}, \ldots, \mathrm{T}_{\mathrm{m}}\right)$ are explicitly treated as unknown and for $\mathrm{i}=1$, $\ldots, \mathrm{m}$, we have $\lambda_{\mathrm{i}}=\mathrm{T}_{\mathrm{i}} / \mathrm{T}$, with $\lambda_{1}<\ldots<\lambda_{\mathrm{m}}<1$. Following the same procedure as before, for each j-partition, $\left\{\mathrm{T}_{1}, \ldots \mathrm{T}_{\mathrm{j}}\right\}$, denoted $\left\{\mathrm{T}_{\mathrm{j}}\right\}$, the associated least-squares estimates of $\alpha^{(\mathrm{j})}, \gamma_{i}^{(j)}$ and the $\mathrm{d}^{(\mathrm{j})}$ are obtained by minimising the sum of squared residuals in the $\mathrm{d}^{(\mathrm{j})}$-differenced models, i.e.,

$$
\sum_{j=1}^{m+1} \sum_{t=T}^{T}\left[\left(1-L^{s}\right)^{d^{(j)}+1} y_{t}-\alpha^{(j)} \tilde{1}_{t}\left(d^{(j)}\right)-\sum_{i=1}^{s-1} \gamma_{i}^{(j)} \widetilde{D}_{i t}\left(d^{(j)}\right)\right]^{2},
$$

where $\hat{\alpha}\left(T_{j}\right), \hat{\gamma}_{i}\left(T_{j}\right)$ and $\hat{d}\left(T_{j}\right)$ denote the resulting estimates. Substituting them in the new objective function and denoting the sum of squared residuals as $\operatorname{RSS}_{\mathrm{T}}\left(\mathrm{T}_{1}, \ldots, \mathrm{T}_{\mathrm{m}}\right)$, the estimated break dates $\left(\hat{T}_{1}, \hat{T}_{2}, \ldots, \hat{T}_{m}\right)$ are obtained by

$$
\min \left(T_{1}, T_{2}, \ldots, T_{m}\right) R S S_{T}\left(T_{1}, \ldots, T_{m}\right)
$$

where the minimisation is again obtained over all partitions $\left(\mathrm{T}_{1}, \ldots, \mathrm{T}_{\mathrm{m}}\right)$.

\section{A Monte Carlo simulation study}

This section examines the finite-sample behaviour of the procedure described in Section 2 by means of Monte Carlo simulations. We generate Gaussian series using the routines GASDEV and RAN3 of Press, Flannery, Teukolsky and Wetterling (1986), with 10,000 replications in each case.

First, we consider the following data generating process: 


$$
\begin{aligned}
& y_{t}=1+3 D_{1 t}+2 D_{2 t}+5 D_{3 t}+x_{t} ; \quad\left(1-L^{4}\right)^{d^{(1)}} x_{t}=u_{t} ; \quad t=1,2, \ldots, T_{b}-1, \\
& y_{t}=0.1+0.3 D_{1 t}+2 D_{2 t}+0.5 D_{3 t}+x_{t} ;\left(1-L^{4}\right)^{d^{(2)}} x_{t}=u_{t} ; \quad t=T_{b}, T_{b}+1, \ldots ., T,
\end{aligned}
$$

with $\mathrm{d}^{(1)}=0.3, \mathrm{~d}^{(2)}=0.7$ and $\mathrm{T}_{\mathrm{b}}=\mathrm{T} / 2$, and follow the procedure described in Section 2 for $\left(d_{j}^{(i)}\right)_{i=1,2}$ - values equal to $0,0.1,0.2, \ldots, 0.9$ and 1 , with the estimated break dates $\mathrm{T}^{*}=\mathrm{T} / 10, \mathrm{~T} / 10+1, \ldots, 9 \mathrm{~T} / 10-1,9 \mathrm{~T} / 10$.

Table 1 displays the percentage of cases when the breakpoint is correctly determined for different sample sizes. It can be seen that, even for a small sample size $(\mathrm{T}=120)$, the procedure correctly detects the break date in a large percentage of cases (47.6\%); this percentage rises to $81.8 \%$ when one time period before and after the break is included. Increasing the sample size the method becomes more accurate - for $\mathrm{T}=$ 720 , with the percentage of cases when the break date is correctly determined being equal to $98.5 \%$.

\section{INSERT TABLES 1 AND 2 ABOUT HERE}

Table 2 focuses on the values for the fractional differencing parameters when $\mathrm{T}^{*}$ is correctly assumed to be $T_{b}$. One can see that in this case, if the sample size is small ( $T$ $=120$ ), the probability of correctly determining the seasonal fractional differencing parameters is very small $(9.3 \%)$ and the highest value $(9.4 \%)$ corresponds to the close alternative $\mathrm{d}^{(1)}=0.2$ and $\mathrm{d}^{(2)}=0.7$. However, when increasing the sample size, the highest probabilities correspond to the true values, being higher than $85 \%$ for $\mathrm{T}=720$. For this size the closest departures are $\mathrm{d}^{(1)}=0.3$ and $\mathrm{d}^{(2)}=0.6(5.4 \%)$, and $\mathrm{d}^{(1)}=0.3$ and $\mathrm{d}^{(2)}=0.8(1.7 \%)$ 


\section{INSERT TABLES 3 AND 4 ABOUT HERE}

Tables 3 and 4 are similar to Tables 1 and 2 and concern the same DGP as before, but with $\mathrm{d}^{(1)}=0.8, \mathrm{~d}^{(2)}=0.4$, and $\mathrm{T}_{\mathrm{b}}=\mathrm{T} / 4$. It is apparent that the probability of correctly determining the break date is slightly higher than in the previous case, though with a larger dispersion across $\mathrm{T}^{*}$ (see Table 3 ). Once more the procedure becomes more accurate as the sample size increases. Focusing now on the fractional differencing parameters (Table 4), we find that, even for the smallest sample size $(\mathrm{T}=120)$, the highest probability $(9 \%)$ corresponds to the true values of the $d$ parameters, and again it increases with $\mathrm{T}$.

\section{An empirical application}

The time series analysed in this section are US Gross Domestic Product (GDP), Personal Consumption Expenditure (PCE) and exports and imports of goods and services, quarterly, seasonally unadjusted, for the time period 1947Q1 - 2005Q4, obtained from the National Economic Accounts, US Department of Commerce, Bureau of Economic Analysis (BEA).

Figure 1 contains the plots of the four raw series. Visual inspection suggests that all them are nonstationary and trending upwards. Unit root tests (Dickey and Fuller, 1979; Phillips and Perron, 1988) on the log-transformed series produce in all cases strong evidence in favour of unit roots. Thus, in the following analysis, we focus on the first differences of the log-transformed data (the growth rate of the series). These appear to be stationary (see Figure 2).

\section{INSERT FIGURES 1 AND 2 ABOUT HERE}


Next, we perform the procedure described in Section 2. Specifically, we consider models of the type given by (5) and (6) with $s=4$, i.e.,

$$
\begin{aligned}
& y_{t}=\alpha^{(1)}+\gamma_{1}^{(1)} D_{1 t}+\gamma_{2}^{(1)} D_{2 t}+\gamma_{3}^{(1)} D_{3 t}+x_{t} ;\left(1-L^{4}\right)^{d^{(1)}} x_{t}=u_{t}, \quad t=1, \ldots, T_{b}-1, \\
& y_{t}=\alpha^{(2)}+\gamma_{1}^{(2)} D_{1 t}+\gamma_{2}^{(2)} D_{2 t}+\gamma_{3}^{(3)} D_{3 t}+x_{t} ; \quad\left(1-L^{4}\right)^{d^{(2)}} x_{t}=u_{t}, \quad t=T_{b, \cdots, T,},
\end{aligned}
$$

and estimate all the parameters for the three cases of white noise $u_{t}$, (in Table 5), AR(1) $\mathrm{u}_{\mathrm{t}}$ (in Table 6) and a seasonal (stationary) AR(1) process of the form: $\mathrm{u}_{\mathrm{t}}=\rho \mathrm{u}_{\mathrm{t}-4}+\varepsilon_{\mathrm{t}}$, with white noise $\varepsilon_{\mathrm{t}}$ (in Table 3 ). Note that, although we do not explicitly provide confidence intervals for the fractional differencing parameters in the procedure presented in Section 2, they can be obtained by using Robinson's (1994) univariate tests (specifically designed for the seasonal case) for each subsample. These values are also displayed in the tables.

Overall, the results suggest that the seasonal patterns in the quarterly time series under examination are not constant for the whole period, if a structural break is taken into account. Starting with the results based on white noise $\mathrm{u}_{\mathrm{t}}$, we find that for GDP and PCE the break takes place at 1981Q1 and the two series behave very similarly: $\mathrm{d}^{(1)}$ (the order of integration for the first subsample) is 0.49 for GDP and 0.48 for PCE, while $\mathrm{d}^{(2)}$ is equal to 0.80 for both series, and the unit root null hypothesis cannot be rejected for these two series in the second subsample. Therefore, there is an increase in the degree of persistence after the break. It is interesting to note that the seasonal dummy variables are statistically significant in both cases before the break, implying the presence of a systematic component. On the contrary, after the break most of the dummies are insignificant, indicating a decrease in the relevance of the systematic component of the seasonality in these series. As suggested by van Dijk et al. (2001), this decrease could 
be due to the use of "just-in-time" techniques that have affected the seasonal cycle in inventory investment.

\section{INSERT TABLE 5 ABOUT HERE}

Moving on to exports of goods and services, the break is found to occur at 1970Q4, with the order of integration of the first subsample being negative (-0.07) and $\mathrm{d}^{(2)}$ being equal to 0.39 . For this series the $\mathrm{I}(0)$ hypothesis cannot be rejected in the first subsample, while both the $\mathrm{I}(0)$ and $\mathrm{I}(1)$ hypotheses are rejected after the break. Once again the dummies are only significant in the first subsample. Finally, for imports, $T_{b}=$ 1953Q1, $\mathrm{d}^{(1)}=0.11$ and $\mathrm{d}^{(2)}=0.28$, the $\mathrm{I}(0)$ hypothesis cannot be rejected in the first subsample, and practically all dummies are insignificant.

Next, we allow for weak dependence in the error term. Specifically, in Table $6 \mathrm{u}_{\mathrm{t}}$ is assumed to be $\operatorname{AR}(1)$. The results are fairly similar to those presented above for the white noise case. More in detail, for GDP and PCE the break takes place at the end of the 1970 s/beginning of the $1980 \mathrm{~s}$, the orders of integration being around 0.5 for the first subsample and close to 0.8 after the break, the unit root null is not rejected in the second subsample and the dummy variables are only statistically significant in the first subsample. Also, note that the AR coefficients are in all cases positive but small. For exports the findings are to some extent different. The break date is now 1952Q4, the order of integration before the break is substantially smaller than previously and significantly different from zero $\left(\mathrm{d}^{(1)}=-0.74\right)$, and all the dummy variables are now significant. For imports, they are no big differences compared to the white noise case.

The break date is the same (1953Q1), $\mathrm{d}^{(1)}$ is slightly negative $(-0.18)$ and $\mathrm{d}^{(2)}$ is positive (0.27), and both are statistically significant. 


\section{INSERT TABLES 6 AND 7 ABOUT HERE}

Finally, we also consider the case of stationary seasonal autoregressions for the error term. This is the most general specification, since it includes in a single framework the three types of seasonality, that is, deterministic seasonality (through the dummy variables), stochastic stationary seasonality (through the seasonal AR coefficients), and fractional/integer differentiation. In Table $7 \mathrm{u}_{\mathrm{t}}$ is assumed to follow a seasonal AR(1) process. The results are consistent with those presented in the earlier tables. For GDP and PCE the break occurs at 1981Q4, and the orders of integration are around 0.6 before the break, and around 0.8 after that date. The seasonal dummy variables are now all significant for both series in both subsamples. For exports, the most important result is that $\mathrm{d}^{(1)}$ is close to $1(-0.99)$, implying then that the original series is $\mathrm{I}(0)$ in the first subsample, with seasonality being captured by a combination of deterministic and stationary stochastic AR components. Finally, for imports the break occurs at 1954Q1, both orders of integration are positive and higher after the break, and there is no evidence of deterministic seasonality.

\section{Conclusions}

This paper considers a general model which allows for both deterministic and stochastic forms of seasonality, including fractional (stationary and nonstationary) orders of integration, and also incorporating endogenously determined structural breaks. Monte Carlo analysis shows that the suggested procedure performs well even in small samples, accurately capturing the seasonal properties of the series, and correctly detecting the break date. As an illustration, the model is estimated for four different US series 
(output, consumption, imports and exports). The results can be summarised as follows. First, we find evidence of a structural break in all the series, with the seasonal pattern changing over time. Second, the systematic component of the seasonality, captured by the seasonal dummies, becomes insignificant in the last period of the sample, while the persistence of the series increases. The decrease in the seasonal amplitude of the series might reflect technological change, changes in institutions or habits, such as the use of the "just-in-time" production techniques (see van Dijk et al., 2001). The fact that the seasonal patterns of the series tend to change over time raises the question of the consequences of using seasonally adjusted series in macroeconomic modelling.

This paper can be extended in several directions. First, other deterministic linear or even non-linear models can be included in the regression models (4) and (5), and the estimation can be carried out adopting the same procedure described here. Second, confidence intervals directly based on our procedure can be obtained using bootstrapping methods, although these are highly computationally intensive, especially if the sample size is large. Another possible extension is to consider different degrees of seasonal integration at each of the frequencies for each subsample. Note that the polynomial $\left(1-\mathrm{L}^{4}\right)$ can be decomposed into $(1-\mathrm{L})(1+\mathrm{L})\left(1+\mathrm{L}^{2}\right)$, and therefore using the polynomial $\left(1-L^{4}\right)^{d}$ implies that the same order of integration $d$ is imposed at all frequencies. However, a problem with this approach is that it is even more computationally intensive, given the greater number of values required in the gridsearch procedure. 


\section{References}

Carlin, J. B. and A. P. Dempster, 1989, Sensitivity analysis of seasonal adjustments: Empirical cases studies, Journal of the American Statistical Association 84, 6-20.

Carlin, J. B., A. P. Dempster and A. B. Jonas, 1985, On methods and moments for Bayesian time series analysis, Journal of Econometrics 30, 67-90.

Dickey, D. A. and W. A. Fuller, 1979, Distribution of the estimators for autoregressive time series with a unit root, Journal of the American Statistical Association 74, 427-431. Dickey, D.A., D.P. Hasza and W.A. Fuller, 1984, Testing for unit roots in seasonal time series, Journal of the American Statistical Association 79, 355-367.

Diebold, F. And A. Inoue, 2001, Long memory and regime switching, Journal of Econometrics 105, 131-159.

Gil-Alana, L.A., 2002, Seasonal long memory in the aggregate output, Economics Letters 74, 333-337.

Gil-Alana, L.A., 2005, Deterministic seasonality versus seasonal fractional integration, Journal of Statistical Planning and Inference 134, 445-461.

Gil-Alana, L.A. and P.M. Robinson, 2001, Testing of seasonal fractional integration in the UK and Japanese consumption and income, Journal of Applied Econometrics 16, 95-114.

Gourieroux, C. and J. Jasiak, 2001, Memory and infrequent breaks, Economics Letters $70,29-41$

Granger, C.W.J. and N. Hyung, 1999, Occasional structural breaks and long memory, Discussion Paper 99-14, University of California, San Diego.

Hylleberg, S., 1986, Seasonality in regression, Academic Press, New York, NY.

Hylleberg, S., R. F. Engle, C. W. J. Granger and B. S. Yoo, 1990, Seasonal integration and cointegration, Journal of Econometrics 44, 215-238. 
Jonas, A. B., 1981, Long memory self similar time series models, unpublished manuscript, Harvard University, Department of Statistics.

Phillips, P.C.B. and P. Perron, 1988, Testing for a unit root in a time series regression, Biometrika 75, 335-346.

Porter-Hudak, S., 1990, An application of the seasonal fractionally differenced model to the monetary aggregate, Journal of the American Statistical Association 85, 338-344.

Press, W.H., B.P. Flannery, S.A. Teukolsky and W.T. Wetterling, 1986, Numerical recipes: The Art of Scientific Computing, Cambridge University Press, Cambridge.

Robinson, P.M., 1994, Efficient tests of nonstationary hypotheses, Journal of the American Statistical Association 89, 1420-1437.

Tam, W. and G. C. Reimsel, 1997, Tests for seasonal moving average unit root in ARIMA models, Journal of the American Statistical Association 92, 725-738.

Van Dijk, D., Strikholm, B. and Teräsvirta, T., 2001, The Effects of institutional and technological change and business cycle fluctuations on seasonal patterns in quarterly industrial production series, Econometric Institute Report EI 2001-12. 


\begin{tabular}{|c|c|c|c|c|}
\hline \multicolumn{5}{|c|}{ TABLE 1 } \\
\hline & $\mathrm{T}=120$ & $\mathrm{~T}=240$ & $\mathrm{~T}=480$ & $\mathrm{~T}=720$ \\
\hline $\mathrm{T} / 2-5$ & 0.013 & 0.004 & 0.000 & 0.000 \\
\hline $\mathrm{T} / 2-4$ & 0.016 & 0.007 & 0.001 & 0.000 \\
\hline $\mathrm{T} / 2-3$ & 0.025 & 0.010 & 0.003 & 0.000 \\
\hline $\mathrm{T} / 2-2$ & 0.045 & 0.021 & 0.006 & 0.001 \\
\hline $\mathrm{T} / 2-1$ & 0.270 & 0.084 & 0.041 & 0.012 \\
\hline $\mathrm{T} / 2$ & $\mathbf{0 . 4 7 6}$ & $\mathbf{0 . 6 5 1}$ & $\mathbf{0 . 9 4 2}$ & $\mathbf{0 . 9 8 5}$ \\
\hline $\mathrm{T} / 2+1$ & 0.072 & 0.019 & 0.007 & 0.002 \\
\hline $\mathrm{T} / 2+2$ & 0.062 & 0.003 & 0.000 & 0.000 \\
\hline $\mathrm{T} / 2+3$ & 0.008 & 0.001 & 0.000 & 0.000 \\
\hline $\mathrm{T} / 2+4$ & 0.012 & 0.000 & 0.000 & 0.000 \\
\hline $\mathrm{T} / 2+5$ & 0.001 & 0.000 & 0.000 & 0.000 \\
\hline
\end{tabular}




\begin{tabular}{|c|c|c|c|c|c|}
\hline \multicolumn{6}{|c|}{ TABLE 2} \\
\hline \multicolumn{6}{|c|}{ Probabilities of detecting the parameters in the model $T_{b}=T / 2, d^{(1)}=0.3$ and $d^{(2)}=0.7$} \\
\hline$d^{(1)}$ & $d^{(2)}$ & $\mathrm{T}=120$ & $\mathrm{~T}=240$ & $\mathrm{~T}=480$ & $\mathrm{~T}=720$ \\
\hline 0.1 & 0.4 & 0.001 & 0.000 & 0.000 & 0.000 \\
\hline 0.1 & 0.5 & 0.006 & 0.002 & 0.000 & 0.000 \\
\hline 0.1 & 0.6 & 0.020 & 0.017 & 0.003 & 0.001 \\
\hline 0.1 & 0.7 & 0.026 & 0.037 & 0.009 & 0.003 \\
\hline 0.1 & 0.8 & 0.012 & 0.012 & 0.002 & 0.000 \\
\hline 0.2 & 0.4 & 0.001 & 0.000 & 0.000 & 0.000 \\
\hline 0.2 & 0.5 & 0.008 & 0.001 & 0.000 & 0.000 \\
\hline 0.2 & 0.6 & 0.047 & 0.102 & 0.065 & 0.014 \\
\hline 0.2 & 0.7 & 0.094 & 0.103 & 0.096 & 0.026 \\
\hline 0.2 & 0.8 & 0.031 & 0.060 & 0.037 & 0.008 \\
\hline 0.3 & 0.4 & 0.001 & 0.000 & 0.000 & 0.000 \\
\hline 0.3 & 0.5 & 0.013 & 0.003 & 0.000 & 0.000 \\
\hline 0.3 & 0.6 & 0.066 & 0.101 & 0.090 & 0.054 \\
\hline 0.3 & 0.7 & 0.093 & 0.306 & 0.569 & 0.858 \\
\hline 0.3 & 0.8 & 0.026 & 0.059 & 0.044 & 0.017 \\
\hline 0.4 & 0.5 & 0.002 & 0.000 & 0.000 & 0.000 \\
\hline 0.4 & 0.6 & 0.010 & 0.016 & 0.007 & 0.001 \\
\hline 0.4 & 0.7 & 0.012 & 0.023 & 0.018 & 0.003 \\
\hline 0.4 & 0.8 & 0.004 & 0.008 & 0.002 & 0.000 \\
\hline 0.4 & 0.9 & 0.001 & 0.000 & 0.000 & 0.000 \\
\hline 0.5 & 0.6 & 0.001 & 0.001 & 0.000 & 0.000 \\
\hline 0.5 & 0.7 & 0.001 & 0.000 & 0.000 & 0.000 \\
\hline
\end{tabular}




\begin{tabular}{|c|c|c|c|c|}
\hline \multicolumn{5}{|c|}{ TABLE 3} \\
\hline \multicolumn{5}{|c|}{ Probabilities of detecting the break date $T_{b}=T / 4$} \\
\hline & $\mathrm{T}=120$ & $\mathrm{~T}=240$ & $\mathrm{~T}=480$ & $\mathrm{~T}=720$ \\
\hline $\mathrm{T} / 4-7$ & 0.002 & 0.001 & 0.000 & 0.000 \\
\hline $\mathrm{T} / 4-6$ & 0.006 & 0.003 & 0.000 & 0.000 \\
\hline $\mathrm{T} / 4-5$ & 0.009 & 0.006 & 0.002 & 0.000 \\
\hline $\mathrm{T} / 4-4$ & 0.003 & 0.004 & 0.001 & 0.000 \\
\hline $\mathrm{T} / 4-3$ & 0.021 & 0.012 & 0.003 & 0.000 \\
\hline $\mathrm{T} / 4-2$ & 0.053 & 0.051 & 0.007 & 0.002 \\
\hline $\mathrm{T} / 4-1$ & 0.143 & 0.130 & 0.019 & 0.005 \\
\hline $\mathbf{T} / 4$ & 0.565 & 0.659 & 0.943 & 0.991 \\
\hline $\mathrm{T} / 4+1$ & 0.114 & 0.083 & 0.013 & 0.002 \\
\hline $\mathrm{T} / 4+2$ & 0.043 & 0.032 & 0.008 & 0.000 \\
\hline $\mathrm{T} / 4+3$ & 0.015 & 0.007 & 0.003 & 0.000 \\
\hline $\mathrm{T} / 4+4$ & 0.007 & 0.007 & 0.001 & 0.000 \\
\hline $\mathrm{T} / 4+5$ & 0.002 & 0.001 & 0.000 & 0.000 \\
\hline $\mathrm{T} / 4+6$ & 0.002 & 0.001 & 0.000 & 0.000 \\
\hline $\mathrm{T} / 4+7$ & 0.002 & 0.001 & 0.000 & 0.000 \\
\hline $\mathrm{T} / 4+8$ & 0.007 & 0.001 & 0.000 & 0.000 \\
\hline $\mathrm{T} / 4+9$ & 0.004 & 0.001 & 0.000 & 0.000 \\
\hline $\mathrm{T} / 4+10$ & 0.002 & 0.000 & 0.000 & 0.000 \\
\hline
\end{tabular}




\begin{tabular}{|c|c|c|c|c|c|}
\hline \multicolumn{6}{|c|}{ TABLE 4} \\
\hline \multicolumn{6}{|c|}{ Probabilities of detecting the parameters in the model $T_{b}=T / 4, d^{(1)}=0.8$ and $d^{(2)}=0.4$} \\
\hline$d^{(1)}$ & $d^{(2)}$ & $\mathrm{T}=120$ & $\mathrm{~T}=240$ & $\mathrm{~T}=480$ & $\mathrm{~T}=720$ \\
\hline 0.5 & 0.2 & 0.006 & 0.000 & 0.000 & 0.000 \\
\hline 0.5 & 0.3 & 0.011 & 0.002 & 0.000 & 0.000 \\
\hline 0.5 & 0.4 & 0.014 & 0.002 & 0.000 & 0.000 \\
\hline 0.5 & 0.5 & 0.005 & 0.000 & 0.000 & 0.000 \\
\hline 0.6 & 0.1 & 0.002 & 0.000 & 0.000 & 0.000 \\
\hline 0.6 & 0.2 & 0.011 & 0.005 & 0.001 & 0.000 \\
\hline 0.6 & 0.3 & 0.015 & 0.004 & 0.000 & 0.000 \\
\hline 0.6 & 0.4 & 0.017 & 0.006 & 0.006 & 0.000 \\
\hline 0.6 & 0.5 & 0.022 & 0.009 & 0.007 & 0.000 \\
\hline 0.7 & 0.1 & 0.003 & 0.000 & 0.000 & 0.000 \\
\hline 0.7 & 0.2 & 0.011 & 0.004 & 0.002 & 0.000 \\
\hline 0.7 & 0.3 & 0.034 & 0.020 & 0.013 & 0.002 \\
\hline 0.7 & 0.4 & 0.050 & 0.032 & 0.099 & 0.007 \\
\hline 0.7 & 0.5 & 0.022 & 0.031 & 0.025 & 0.003 \\
\hline 0.7 & 0.6 & 0.006 & 0.001 & 0.000 & 0.000 \\
\hline 0.8 & 0.1 & 0.003 & 0.000 & 0.000 & 0.000 \\
\hline 0.8 & 0.2 & 0.018 & 0.024 & 0.011 & 0.001 \\
\hline 0.8 & 0.3 & 0.060 & 0.044 & 0.095 & 0.087 \\
\hline 0.8 & 0.4 & 0.090 & 0.292 & 0.477 & 0.850 \\
\hline 0.8 & 0.5 & 0.024 & 0.040 & 0.062 & 0.015 \\
\hline 0.8 & 0.6 & 0.007 & 0.002 & 0.000 & 0.000 \\
\hline 0.9 & 0.1 & 0.003 & 0.002 & 0.000 & 0.000 \\
\hline 0.9 & 0.2 & 0.015 & 0.008 & 0.003 & 0.000 \\
\hline 0.9 & 0.3 & 0.037 & 0.033 & 0.024 & 0.004 \\
\hline 0.9 & 0.4 & 0.048 & 0.029 & 0.088 & 0.012 \\
\hline 0.9 & 0.5 & 0.016 & 0.021 & 0.020 & 0.010 \\
\hline 0.9 & 0.5 & 0.002 & 0.001 & 0.000 & 0.000 \\
\hline 1.0 & 0.2 & 0.001 & 0.000 & 0.010 & 0.000 \\
\hline 1.0 & 0.3 & 0.009 & 0.001 & 0.000 & 0.000 \\
\hline 1.0 & 0.4 & 0.012 & 0.003 & 0.000 & 0.000 \\
\hline 1.0 & 0.5 & 0.001 & 0.000 & 0.000 & 0.000 \\
\hline
\end{tabular}




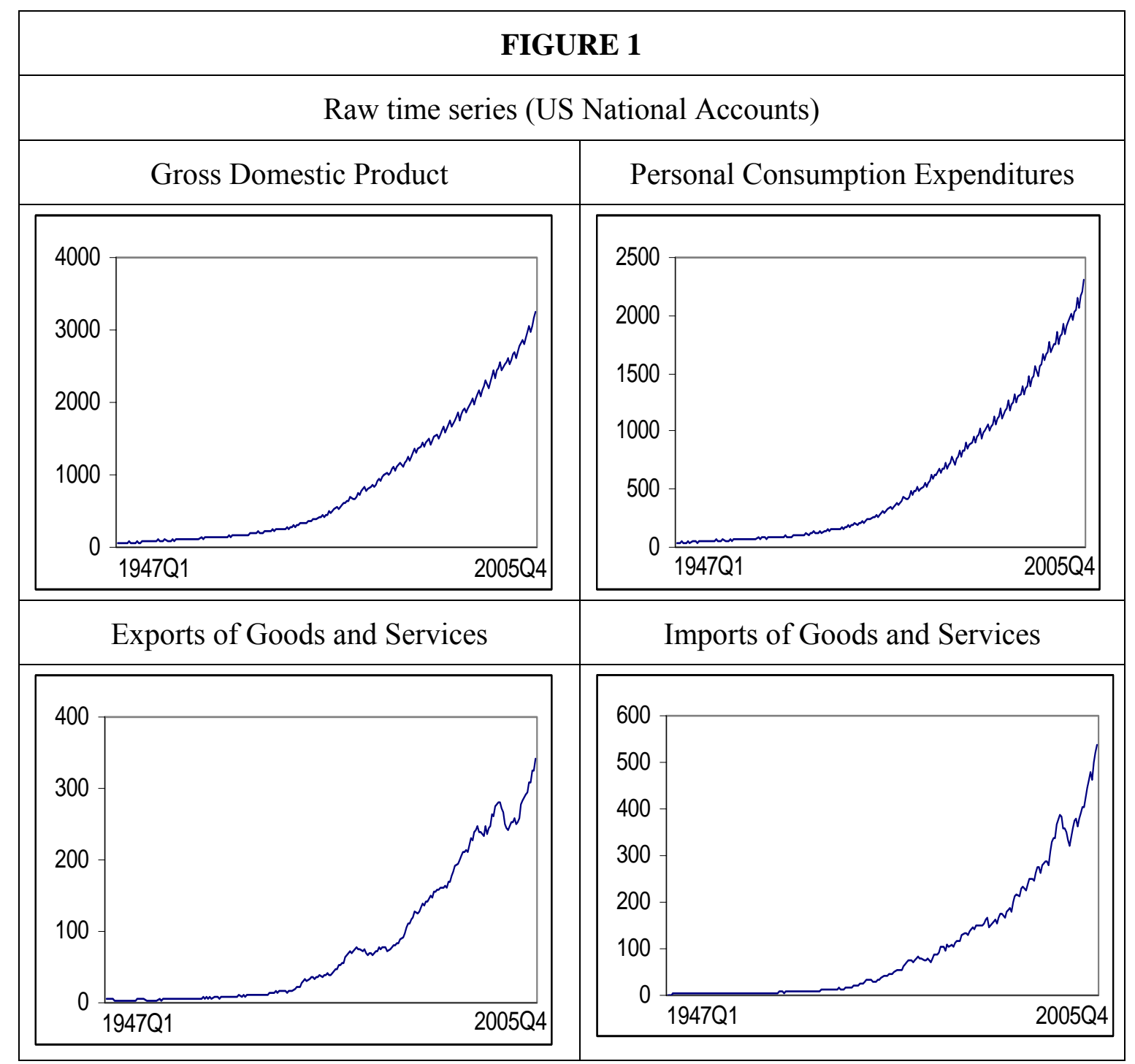




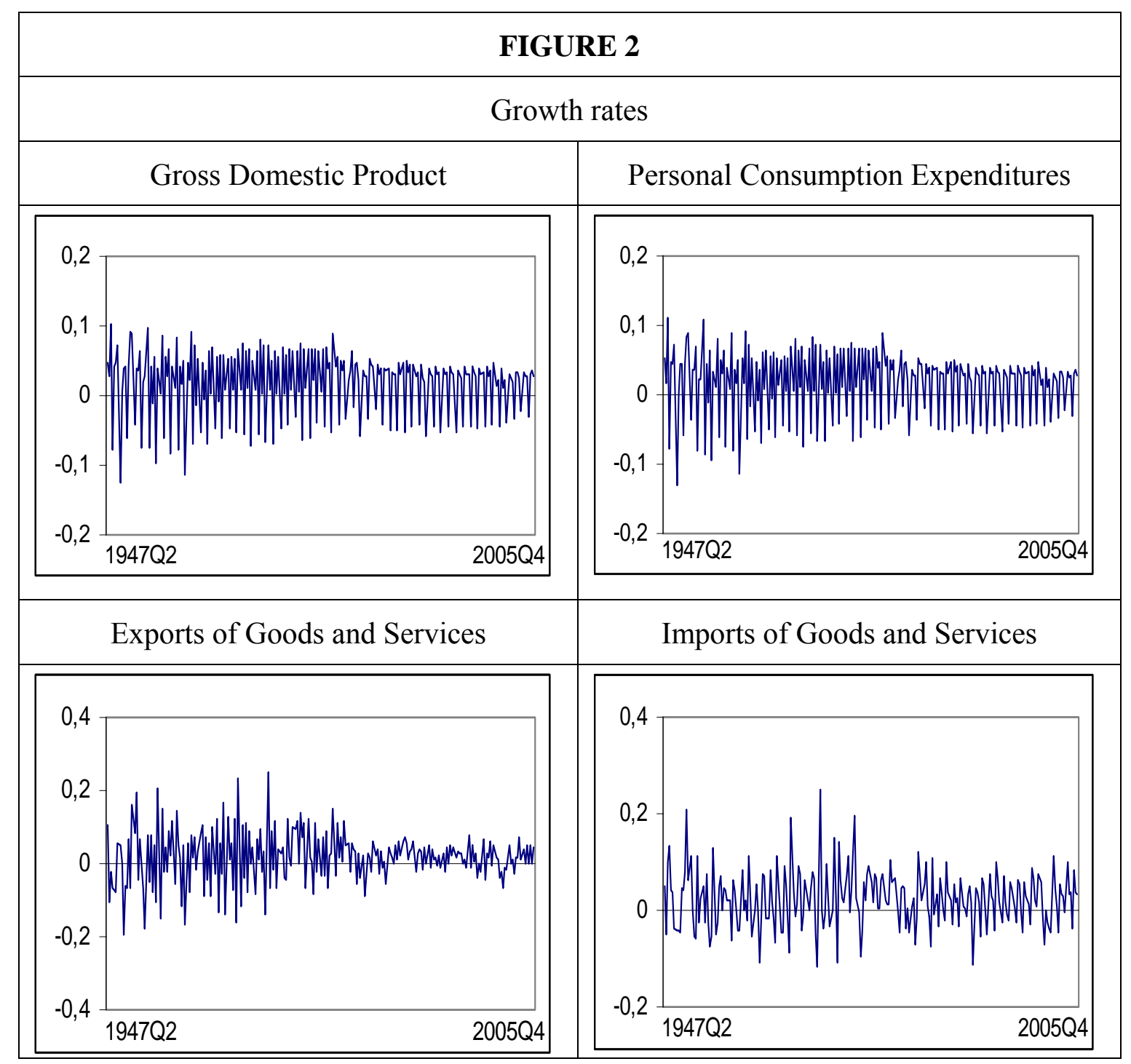




\begin{tabular}{|c|c|c|c|c|c|}
\hline \multicolumn{6}{|c|}{ TABLE 5} \\
\hline \multicolumn{6}{|c|}{ Estimates of the parameter coefficients: White noise case } \\
\hline & & GDP & PCE & EXPORTS & IMPORTS \\
\hline \multirow{5}{*}{$\begin{array}{c}\text { First } \\
\text { Subsample }\end{array}$} & $d^{(1)}$ & $\begin{array}{c}0.49 \\
(0.17,0.62)\end{array}$ & $\begin{array}{c}0.48 \\
(0.15,0.59)\end{array}$ & $\begin{array}{c}-0.07 \\
(-0.37,0.12)\end{array}$ & $\begin{array}{c}-0.11 \\
(-0.34,0.19)\end{array}$ \\
\hline & $\alpha^{(1)}$ & $\begin{array}{c}-0.0834 \\
(-7.05)\end{array}$ & $\begin{array}{c}-0.0840 \\
(-7.06)\end{array}$ & $\begin{array}{l}0.0380 \\
(-3.48)\end{array}$ & $\begin{array}{c}0.0374 \\
(1.31)\end{array}$ \\
\hline & $\gamma_{1}^{(1)}$ & $\begin{array}{l}0.1171 \\
(7.01)\end{array}$ & $\begin{array}{l}0.1191 \\
(7.09)\end{array}$ & $\begin{array}{l}0.1167 \\
(7.65)\end{array}$ & $\begin{array}{l}-0.0518 \\
(-1.35)\end{array}$ \\
\hline & $\gamma_{2}^{(1)}$ & $\begin{array}{l}0.0980 \\
(5.86)\end{array}$ & $\begin{array}{r}0.0947 \\
(5.63)\end{array}$ & $\begin{array}{c}-0.0630 \\
(-4.13)\end{array}$ & $\begin{array}{l}-0.0476 \\
(-1.24)\end{array}$ \\
\hline & $\gamma_{3}^{(1)}$ & $\begin{array}{c}0.1469 \\
(8.79)\end{array}$ & $\begin{array}{c}0.1492 \\
(8.87)\end{array}$ & $\begin{array}{l}0.1028 \\
(6.67)\end{array}$ & $\begin{array}{l}-0.0434 \\
(-1.13)\end{array}$ \\
\hline \multicolumn{2}{|c|}{ Time of the break } & 1981Q1 & 1981Q1 & 1970Q4 & 1953Q1 \\
\hline \multirow{5}{*}{$\begin{array}{c}\text { Second } \\
\text { Subsample }\end{array}$} & $d^{(2)}$ & $\begin{array}{c}0.80 \\
(0.56,1.01)\end{array}$ & $\begin{array}{c}0.80 \\
(0.44,1.00)\end{array}$ & $\begin{array}{c}0.39 \\
(0.17,0.63)\end{array}$ & $\begin{array}{c}0.28 \\
(0.05,0.37)\end{array}$ \\
\hline & $\alpha^{(2)}$ & $\begin{array}{c}0.0104 \\
(1.97)\end{array}$ & $\begin{array}{c}0.0105 \\
(1.92)\end{array}$ & $\begin{array}{l}0.0105 \\
(0.74)\end{array}$ & $\begin{array}{c}-0.0188 \\
(-1.38)\end{array}$ \\
\hline & $\gamma_{1}^{(2)}$ & $\begin{array}{c}0.0173 \\
(2.27)\end{array}$ & $\begin{array}{l}0.0176 \\
(2.30)\end{array}$ & $\begin{array}{c}0.0136 \\
(0.67)\end{array}$ & $\begin{array}{c}0.0724 \\
(3.66)\end{array}$ \\
\hline & $\gamma_{2}^{(2)}$ & $\begin{array}{l}0.0118 \\
(1.54)\end{array}$ & $\begin{array}{l}0.0116 \\
(1.52)\end{array}$ & $\begin{array}{c}-0.0385 \\
(-1.89)\end{array}$ & $\begin{array}{l}0.0173 \\
(0.87)\end{array}$ \\
\hline & $\gamma_{3}^{(2)}$ & $\begin{array}{c}0.0061 \\
(0.80)\end{array}$ & $\begin{array}{c}0.0059 \\
(0.78)\end{array}$ & $\begin{array}{c}0.0194 \\
(0.95)\end{array}$ & $\begin{array}{l}-0.0131 \\
(-0.66)\end{array}$ \\
\hline
\end{tabular}




\begin{tabular}{|c|c|c|c|c|c|}
\hline \multicolumn{6}{|c|}{ TABLE 6} \\
\hline \multicolumn{6}{|c|}{ Estimates of the parameter coefficients: AR(1) case } \\
\hline & & GDP & PCE & EXPORTS & IMPORTS \\
\hline \multirow{6}{*}{$\begin{array}{c}\text { First } \\
\text { Subsample }\end{array}$} & $\mathrm{d}^{(1)}$ & $\begin{array}{c}0.50 \\
(0.22,0.71)\end{array}$ & $\begin{array}{c}0.49 \\
(0.24,0.80)\end{array}$ & $\begin{array}{c}-0.74 \\
(-0.94,-0.13)\end{array}$ & $\begin{array}{c}-0.18 \\
(-0.55,-0.02)\end{array}$ \\
\hline & $\alpha^{(1)}$ & $\begin{array}{c}-0.0849 \\
(-7.15)\end{array}$ & $\begin{array}{r}-0.0842 \\
(-7.07)\end{array}$ & $\begin{array}{l}0.0118 \\
(-0.96)\end{array}$ & $\begin{array}{l}0.0365 \\
(1.41)\end{array}$ \\
\hline & $\gamma_{1}^{(1)}$ & $\begin{array}{c}0.1206 \\
(7.18)\end{array}$ & $\begin{array}{c}0.1193 \\
(7.09)\end{array}$ & $\begin{array}{c}0.0405 \\
(2.56)\end{array}$ & $\begin{array}{l}-0.0499 \\
(-1.45)\end{array}$ \\
\hline & $\gamma_{2}^{(1)}$ & $\begin{array}{c}0.0983 \\
(5.85)\end{array}$ & $\begin{array}{c}0.0945 \\
(5.63)\end{array}$ & $\begin{array}{c}-0.1058 \\
(-6.69)\end{array}$ & $\begin{array}{l}-0.0458 \\
(-1.33)\end{array}$ \\
\hline & $\gamma_{3}^{(1)}$ & $\begin{array}{c}0.1478 \\
(8.79)\end{array}$ & $\begin{array}{l}0.1491 \\
(8.87)\end{array}$ & $\begin{array}{l}0.0340 \\
(1.95)\end{array}$ & $\begin{array}{l}-0.0422 \\
(-1.22)\end{array}$ \\
\hline & AR coeff. & 0.271 & 0.158 & 0.574 & 0.290 \\
\hline \multicolumn{2}{|c|}{ Time of the break } & 1979Q2 & 1981Q1 & 1952Q4 & 1953Q1 \\
\hline \multirow{6}{*}{$\begin{array}{c}\text { Second } \\
\text { Subsample }\end{array}$} & $d^{(2)}$ & $\begin{array}{c}0.73 \\
(0.52,1.02)\end{array}$ & $\begin{array}{c}0.83 \\
(0.56,1.04) \\
\end{array}$ & $\begin{array}{c}0.31 \\
(0.05,0.44)\end{array}$ & $\begin{array}{c}0.27 \\
(\mathbf{0 . 0 5}, \mathbf{0 . 4 1 )}\end{array}$ \\
\hline & $\alpha^{(2)}$ & $\begin{array}{l}0.0071 \\
(1.06)\end{array}$ & $\begin{array}{l}0.0112 \\
(1.83)\end{array}$ & $\begin{array}{l}-0.0166 \\
(-1.08)\end{array}$ & $\begin{array}{l}-0.0200 \\
(-1.55)\end{array}$ \\
\hline & $\gamma_{1}^{(2)}$ & $\begin{array}{l}0.0206 \\
(2.40)\end{array}$ & $\begin{array}{c}0.0172 \\
(2.25)\end{array}$ & $\begin{array}{l}0.0622 \\
(2.80)\end{array}$ & $\begin{array}{r}0.0740 \\
(3.93)\end{array}$ \\
\hline & $\gamma_{2}^{(2)}$ & $\begin{array}{l}0.0099 \\
(1.16)\end{array}$ & $\begin{array}{c}0.0114 \\
(1.49)\end{array}$ & $\begin{array}{c}-0.0448 \\
(-2.02)\end{array}$ & $\begin{array}{l}0.0191 \\
(1.01)\end{array}$ \\
\hline & $\gamma_{3}^{(2)}$ & $\begin{array}{l}0.0200 \\
(2.34)\end{array}$ & $\begin{array}{l}0.0055 \\
(0.71)\end{array}$ & $\begin{array}{l}0.0593 \\
(2.68)\end{array}$ & $\begin{array}{l}-0.0117 \\
(-0.62)\end{array}$ \\
\hline & AR coeff. & 0.341 & 0.231 & -0.198 & 0.026 \\
\hline
\end{tabular}




\begin{tabular}{|c|c|c|c|c|c|}
\hline \multicolumn{6}{|c|}{ TABLE 7} \\
\hline \multicolumn{6}{|c|}{ Estimates of the parameter coefficients: Seasonal AR(1) case } \\
\hline & & GDP & PCE & EXPORTS & IMPORTS \\
\hline \multirow{6}{*}{$\begin{array}{c}\text { First } \\
\text { Subsample }\end{array}$} & $\mathrm{D}^{(1)}$ & $\begin{array}{c}0.61 \\
(0.45,0.72)\end{array}$ & $\begin{array}{c}0.57 \\
(0.41,0.70)\end{array}$ & $\begin{array}{c}-0.99 \\
(-1.42,-0.17)\end{array}$ & $\begin{array}{c}0.28 \\
(-0.14,0.43)\end{array}$ \\
\hline & $\alpha^{(1)}$ & $\begin{array}{c}-0.0833 \\
(-5.92)\end{array}$ & $\begin{array}{c}-0.0084 \\
(-6.11)\end{array}$ & $\begin{array}{l}0.0168 \\
(-5.83)\end{array}$ & $\begin{array}{l}0.0381 \\
(0.95)\end{array}$ \\
\hline & $\gamma_{1}^{(1)}$ & $\begin{array}{c}0.1194 \\
(6.01)\end{array}$ & $\begin{array}{c}0.1218 \\
(6.26)\end{array}$ & $\begin{array}{l}0.0759 \\
(19.76)\end{array}$ & $\begin{array}{l}-0.0289 \\
(-0.52)\end{array}$ \\
\hline & $\gamma_{2}^{(1)}$ & $\begin{array}{l}0.1047 \\
(5.27)\end{array}$ & $\begin{array}{c}0.0988 \\
(5.07)\end{array}$ & $\begin{array}{l}-0.0853 \\
(-20.93)\end{array}$ & $\begin{array}{l}-0.0528 \\
(-0.95)\end{array}$ \\
\hline & $\gamma_{3}^{(1)}$ & $\begin{array}{l}0.1581 \\
(7.95)\end{array}$ & $\begin{array}{c}0.1585 \\
(8.14)\end{array}$ & $\begin{array}{l}0.0769 \\
(18.89)\end{array}$ & $\begin{array}{l}-0.0420 \\
(-0.76)\end{array}$ \\
\hline & S. AR coeff. & -0.282 & -0.214 & 0.527 & -0.607 \\
\hline \multicolumn{2}{|c|}{ Time of the break } & 1981Q1 & 1981Q1 & 1958Q3 & 1954Q1 \\
\hline \multirow{6}{*}{$\begin{array}{c}\text { Second } \\
\text { Subsample }\end{array}$} & $d^{(2)}$ & $\begin{array}{c}0.84 \\
(0.64,1.13) \\
\end{array}$ & $\begin{array}{c}0.84 \\
(0.64,1.11) \\
\end{array}$ & $\begin{array}{c}0.31 \\
(0.13,0.39) \\
\end{array}$ & $\begin{array}{c}0.40 \\
(0.27,0.61) \\
\end{array}$ \\
\hline & $\alpha^{(2)}$ & $\begin{array}{l}0.0118 \\
(1.92)\end{array}$ & $\begin{array}{l}0.0119 \\
(1.94)\end{array}$ & $\begin{array}{l}-0.0026 \\
(-0.16)\end{array}$ & $\begin{array}{l}-0.0105 \\
(-0.60)\end{array}$ \\
\hline & $\gamma_{1}^{(2)}$ & $\begin{array}{l}0.0166 \\
(2.17)\end{array}$ & $\begin{array}{l}0.0169 \\
(2.20)\end{array}$ & $\begin{array}{c}0.0466 \\
(1.98)\end{array}$ & $\begin{array}{l}0.0650 \\
(2.61)\end{array}$ \\
\hline & $\gamma_{2}^{(2)}$ & $\begin{array}{l}0.0113 \\
(1.68) \\
\end{array}$ & $\begin{array}{c}0.0112 \\
(1.66) \\
\end{array}$ & $\begin{array}{c}-0.0507 \\
(-2.16)\end{array}$ & $\begin{array}{r}0.0053 \\
(0.21) \\
\end{array}$ \\
\hline & $\gamma_{3}^{(2)}$ & $\begin{array}{c}0.0052 \\
(0.68)\end{array}$ & $\begin{array}{r}0.0050 \\
(0.65)\end{array}$ & $\begin{array}{c}0.0421 \\
(1.79)\end{array}$ & $\begin{array}{c}-0.0148 \\
(-0.59)\end{array}$ \\
\hline & S. AR coeff. & -0.104 & -0.105 & -0.163 & -0.265 \\
\hline
\end{tabular}

